\title{
Autocatalysis, Entropic Aspects and the Martensite Transformation Curve in Iron-Base Alloys
}

\author{
José Roberto Costa Guimarães ${ }^{a, b}$, Paulo Rangel Rios ${ }^{a *}$ \\ ${ }^{a}$ Escola de Engenharia Industrial Metalúrgica de Volta Redonda, Universidade Federal Fluminense- \\ UFF, Av. dos Trabalhadores, 420, 27255-125, Volta Redonda, RJ, Brasil \\ ${ }^{b}$ Mal. Moura 338H/22C, 05641-000, São Paulo, SP, Brasil
}

Received: June 17, 2016; Revised: November 16, 2016; Accepted: November 21, 2016

\begin{abstract}
This study advances a methodology that consolidates the description of time-dependent (isothermal) as well as time-independent (athermal) martensitic transformation curves. Our model is applied in an extended 3-space, thus permitting inclusion of the effects of autocatalysis on nucleation to be distinguished from the initiation of the transformation, as influenced by entropic barriers. Autocatalysis is then considered as a mechanism for circumventing the effect of the latter. The utility of this proposed mathematical formalism was validated with a database consisting of seven different steels that transform athermally or isothermally.
\end{abstract}

Keywords: martensitic transformations, phase transformations, kinetics, athermal martensite, isothermal martensite

\section{Introduction}

The formal description of martensitic transformation kinetics remains an active topic in steel research, now exceeding nearly a century of interest ${ }^{1-12}$. The equations predicting this phenomenon invariably contain fitting parameters. The relative simplicity of the Koistinen-Marburger equation ${ }^{2}$ is frequently relied upon in the design and processing of steels that exhibit time-independent, athermal martensite transformation. Recently, an interest has developed to optimize the performance of steels that undergo time-dependent, isothermal martensite transformations.

The purpose of this communication is to provide a basis for rationalizing martensite transformation curves in terms of heterogeneous autocatalytic aspects that are associated with steel processing.

\subsection{Formalism}

Martensite transformations in steel proceed by multiple nucleation events, rather than by the growth of a few units. Coarsening and coalescence after the units activate are rarely described.

The displacive character of martensite requires that a group of highly correlated atoms simultaneously traverse the reaction path ${ }^{13}$. Since atomic mobility in the austenite opposes the existence of highly correlated atomic clusters, entropic barriers exist that delimit initiation of the martensite transformation ${ }^{14-16}$. Consequently, martensite nucleation occurs heterogeneously at sites where the atomic displacements are somehow limited ${ }^{15}$, thus requiring the appearance of transformation-embryos, e.g., existence of lattice faults ${ }^{17}$.
The autocatalysis is ascribable to structural perturbations introduced by a previously formed unit. Pursuant to the view that martensitic transformation in steel is nucleation-controlled, it is conceivable during this transformation that the population of martensite nucleation sites balance the initial autocatalysis, and those sites that propagated, or were disturbed by the transformation ${ }^{18}$. This balance concept, proposed by Raghavan and Entwisle ${ }^{18}$, was later modified by Pati and Cohen ${ }^{19}$, who introduced the classical "exhaustion factor" into their equation. However, the issue of microstructural evolution remains a major obstacle in the application of the balance model. Here we propose applying Avrami's extended-space approach $^{20-24}$ to analyze heterogeneous martensite nucleation events that occur during martensitic transformations. In extended 3-space, as defined in ${ }^{20-24}$, both impingement and exhaustion of microstructure units are ignored, so that the temporal sequence of nucleation events does not further complicate the modeling of transformation curves.

With that approach, the number density of martensite nucleation sites along the transformation is expressed as

$$
n_{V X}=n_{V}+\left(\alpha_{X}-1\right) N_{V X}
$$

where the subscript, " $X$ ", marks parameters and variables in the extended space realm. In Eq. (1), $n_{V}$ and $N_{V}$ represent the number density of nucleation sites and martensite units, respectively. Note that the initial number density of sites, $n_{I V}$ is not an extended parameter. But, $\alpha_{\mathrm{x}}$ is the extended autocatalytic factor.

We express the variation in the number density of extended martensite units as,

$$
d N_{V X}=n_{V X} d \xi,
$$


where $\xi$ is a normalized temporal variable. Substituting Eq. (1) for $n_{V X}$ into Eq. (2), recalling that the extended volume fraction transformed, $V_{V X}=V_{X} N_{V X}$, and expressing the mean extended unit volume as a fraction, $m$, of the mean austenite grain volume, $q$, conforming with the displacive aspects of the martensite transformation, $v_{X}=m q$, gives a differential equation for the fraction transformed in extended space, the integration of which yields the extended martensite transformation.

$$
\frac{d V_{V X}}{\left(M_{X}+\left(\alpha_{X}-1\right) V_{V X}\right)}=d \xi
$$

Here, $M_{X}=m q n_{I V}$, calculates the contribution of the $n_{I V}$ initial nucleation sites to the extended martensite fraction transformed, $V_{V X}$. Note that by admitting a suitable thermodynamic-kinetic path one may infer the values of $M_{X}$ and $\alpha_{X}$ from the transformation curve. Vice versa, if the values of $M_{X}$ and $\alpha_{X}$ were previously known, the thermodynamickinetic path may be described as a function of the fraction transformed.

The translation of that into the actual martensite volume fraction transformed $V_{V}$ requires a relationship that maps extended parameters to real parameters. Absent an exact solution $^{23,24}$ for that map, the JMAK relationship ${ }^{20-22}$ is frequently invoked as a suitable approximation to accomplish the parametric transformation,

$$
V_{V X}=\ln \left(1-V_{V}\right)^{-1},
$$

The same qualification applies to the classical "exhaustion factor", 1- $V_{V}$.

Note, if the transformation saturates short of a material fraction transformed of unity, then normalization is required. Henceforth, bearing these qualifications, we shall use the JMAK relationship in the sequence.

\subsection{Time-dependent ("isothermal") transformation}

It is generally accepted that the isothermal martensite reaction path has a single barrier. Thence we write,

$$
d \xi=v \exp \left(-Q_{N} / k T\right) d \tau
$$

where $v$ and $\tau$ are the frequency factor and the reaction time, respectively. $Q_{N}$ is the activation energy for martensite nucleation, $k$ is the Boltzmann constant, and $T$ is the absolute temperature. Substituting Eq.(5) into Eq.(3) followed by integration yields

$$
\begin{aligned}
& \ln \left(1+\frac{\left(\alpha_{X}-1\right)}{M_{X}} V_{V X}\right)^{1 /\left(\alpha_{X}-1\right)}= \\
& v \exp \left(-Q_{N} / k T\right) \tau+X
\end{aligned}
$$

where the parameter $X$ is included to compensate for the incubation time uncertainty. Thence, $\mathrm{V}_{\mathrm{V}}$ can be calculated using Eq.(4) and Eq.(6).

\subsection{Time-independent ("athermal") transformation}

The time-independent martensite transformation, normally observed in commercial steels, takes place during austenite cooling. Considering the range of temperatures within which nucleation events occur, one can tentatively set $d \xi=d \Delta G_{\gamma M} / \Delta G_{\gamma M}$ and recast Eq.(3) as

$$
\int_{V V X} \frac{d V_{V X}}{\left(M_{X}+\left(\alpha_{X}-1\right) \cdot V_{V X}\right)}=\int_{\Delta G \gamma M} \frac{d \Delta G_{\gamma M}}{G_{\gamma M}}
$$

In a previous paper ${ }^{25}$ it was demonstrated that the spread of martensite transformation over particles of $\mathrm{Fe}-30 \mathrm{wt} \% \mathrm{Ni}$ quenched to different temperatures ${ }^{26}$ was compatible with the probability of finding a potential site to initiate the transformation in the material at temperature $T$

$$
\frac{n_{I V}^{T}}{n_{V O}}=\left(\frac{\Delta G_{\gamma M}-\Delta G_{\gamma M 0}}{k T}\right)
$$

where $n_{V 0}$ is the overall number density of suitable defects in the material. The product of the Boltzmann constant by the absolute temperature, $k T$, is a normalization factor. Eq.(8) shows that that martensitic transformation takes place when its chemical driving force, $\Delta G_{\gamma M}$ (negative of Gibbs Free Energy) increases beyond a threshold $\Delta G_{\gamma M 0}=\Delta G_{\gamma M}\left(T^{*}\right)$.

One may define a temperature $T^{*}$ as the highest temperature at which martensite embryos become viable. Thence, the martensite nucleation is also viable in the range of temperatures $T^{*}>M_{S}>T$, noting that the martensite-austenite equilibrium temperature is $\mathrm{T}_{0}{ }^{\gamma M}>T^{*}$. It is reasonable to suppose that $\Delta G_{\gamma M}$ varies linearly with transformation temperature so that $\frac{d \Delta G_{\gamma M}}{\Delta G_{\gamma M}}=\frac{-\Delta S_{\gamma M} \cdot d T}{\Delta S_{\gamma M}\left(T^{*-T}\right)}=\frac{d T}{T^{*-T}}$ where $\Delta S_{\gamma}$ stands for the pertinent change in chemical entropy. Substituting this relationship into Eq.(7) gives

$$
\int_{0}^{V_{V X}} \frac{d V_{V X}}{\left(M_{X}+\left(\alpha_{X}-1\right) \cdot V_{V X}\right)}=-\int_{T^{*}}^{T} \frac{d T}{T^{*}-T}
$$

However, the integration of the left side of Eq.(9) requires the knowledge of the influence of the temperature variation of $n_{I V}$ on $M_{X}$ during continuous cooling. In absence of an exact description for this, and lacking experimental values for $m$, we use a mean value of, $M_{X}, \bar{M}_{X}$, in Eq.(9) and integrate

$$
\begin{aligned}
& V_{V X}=\frac{\bar{M}_{X}}{\alpha_{X}-1}\left(\left(\frac{T *-T}{T *-M_{S}}\right)^{\alpha{ }^{-1}}-1\right) \\
& V_{V} \text { follows from Eq.(4). }
\end{aligned}
$$




\section{Validation of the formalism}

As in previous works, we sought independent data to validate the models. The compiled data were obtained by scanning and digitizing the graphs in the referenced papers, and reviewing these digitalized data for inconsistencies. For the time-dependent ("isothermal" transformation) we refer to Pati and Cohen ${ }^{19} \mathrm{Fe}-23 \mathrm{wt} \% \mathrm{Ni}-4 \mathrm{wt} \% \mathrm{Mn}$ dataset. Complementary, we considered the transformation in a hypo-eutectoid C-SiMn steel below the $M_{S}{ }^{27,28}$ and in a Fe-12wt\% $\%$ r- $9 \mathrm{wt} \% \mathrm{Ni}$ maraging steel transformed under magnetic field ${ }^{29}$. For the time-independent ("athermal") transformation we refer to the data typical of the plain carbon steels $\mathrm{Fe}-0.46 \mathrm{wt} \% \mathrm{C}$, $\mathrm{Fe}-0.66 \mathrm{wt} \% \mathrm{C}$ and $\mathrm{Fe}-0.80 \mathrm{wt} \% \mathrm{C}$, described by S.M.C. Van Bohemen and J. Sietsma ${ }^{9}$. Complementary we considered a high $\mathrm{C} \mathrm{Cr} \mathrm{steel}^{30}$ and $\mathrm{Fe}-31 \mathrm{wt} \% \mathrm{Ni}-0.01 \mathrm{wt} \% \mathrm{C}^{31}$. Error bars with a reasonable relative error of $5 \%$ were inserted in all experimental data as the data lacked error bars.

\subsection{Time-dependent ("isothermal") transformation}

The Table 1 lists the parameters used to fit the data to the model. Although this table lists values of $\alpha_{X}=1$ the best-fits were achieved with $\alpha_{X} \approx 1$ because Eq.(7) diverges at $\alpha_{X}=1$. We estimated the value of $m$ by the ratio of the martensite unit mean volume on the austenite grain ${ }^{19,32} \cdot M_{X}=m q n^{T}{ }_{I V}$ was calculated using the typical value of $n_{V 0}=10^{4} \mathrm{~mm}^{-3}$ into Eq.(8); $\alpha_{X}$ and $\mathrm{T}^{*}$ were fitted. The tabulated values of $X$ resulted from the regression procedure and should not be considered to calculate "incubation times" in view of the hardship to digitalize the initial tails in the published charts. As frequently done, we equated the frequency factor to lattice frequency $\left(10^{13} \mathrm{~s}^{-1}\right)$, although we acknowledge that a lower frequency would be more compatible with the displacive aspect of the transformation ${ }^{3,33}$. The frequency factor influences the magnitude of the obtained apparent activation energy without upsetting its temperature dependence. Despite the approximations mentioned in the foregoing, the graphs show fitting correlations $\mathrm{R}^{2} \geq 0.97$. The fitting of the database using the parameters tabulated in Table 1 are shown in Figure 1(a-d).

Referring to the $\mathrm{Fe}-23 \mathrm{wt} \% \mathrm{Ni}-4 \mathrm{wt} \% \mathrm{Mn}$ data, note that the obtained apparent activation energies, $Q_{N}$, are $20 \%$ less than the values in ${ }^{19}$. Bearing the different formalisms, these results can be considered comparable. More important is the similarity in the variation of the activation energies with the transformation driving force - see Table 1 and Figure 2. The linear relationship between $Q_{N}$ and the driving force is corroborated by the influence of an external magnetic field on the isothermal transformation of $\mathrm{Fe}-12 \mathrm{wt} \% \mathrm{Cr}-9 \mathrm{wt} \% \mathrm{Ni}$ also evident in Table 1.

Continuing, one considers the time-variation of the parameter $P_{X}=V_{V X} / M_{X}$ depicted in Figure 3. This parameter estimates the volumetric contribution of the autocatalysis

Table 1: Time-dependent transformations

\begin{tabular}{|c|c|c|c|c|c|c|c|}
\hline \multicolumn{8}{|c|}{$\mathrm{Fe}-23 \mathrm{wt} \% \mathrm{Ni}-4 \mathrm{wt} \% \mathrm{Mn}^{19}$} \\
\hline \multicolumn{2}{|c|}{$d \gamma=0.025 \mathrm{~mm}$} & \multirow{2}{*}{$\frac{\mathrm{m}=0.04}{\mathrm{X}}$} & \multicolumn{2}{|l|}{$\mathrm{T}^{*}=200 \mathrm{~K}$} & \multirow[b]{2}{*}{$M_{X}$} & \multirow[b]{2}{*}{$\dot{P}_{X} \mathrm{~s}^{-1}$} & \multirow[b]{2}{*}{$R^{2}$} \\
\hline $\mathrm{T}, \mathrm{K}$ & $Q_{n} \mathrm{~J} /$ event & & $\alpha_{\underline{X}}$ & $\mathrm{n}_{\mathrm{V}}^{\mathrm{T}} \mathrm{mm}^{-3}$ & & & \\
\hline 133 & $4.46 \times 10^{-20}$ & $-1.04 \times 10^{-1}$ & 1.00 & $1.52 \times 10^{3}$ & $1.25 \times 10^{-3}$ & 338.02 & 0.97 \\
\hline 148 & $4.65 \times 10^{-20}$ & $-5.45 \times 10^{-2}$ & 1.00 & $1.06 \times 10^{3}$ & $5.41 \times 10^{-4}$ & 1410.00 & 0.98 \\
\hline 158 & $5.25 \times 10^{-20}$ & $-1.09 \times 10^{-1}$ & 1.00 & $8.04 \times 10^{2}$ & $4.09 \times 10^{-4}$ & 589.47 & 0.99 \\
\hline 168 & $5.54 \times 10^{-20}$ & $5.41 \times 10^{-3}$ & 1.00 & $5.76 \times 10^{2}$ & $1.05 \times 10^{-4}$ & 744.72 & 0.99 \\
\hline 183 & $6.16 \times 10^{-20}$ & $-1.56 \times 10^{-2}$ & 1.00 & $2.81 \times 10^{2}$ & $5.11 \times 10^{-5}$ & 291.48 & 0.99 \\
\hline 193 & $7.11 \times 10^{-20}$ & $8.42 \times 10^{-3}$ & 1.00 & $1.10 \times 10^{2}$ & $1.99 \times 10^{-5}$ & 27.64 & 0.98 \\
\hline \multicolumn{8}{|c|}{ Fe-1.5wt $\% \mathrm{Mn}-1.5 w t \%$ Si-0.3wt $\%$ Al-0.2wt $\% \mathrm{C}^{27}$} \\
\hline \multicolumn{2}{|c|}{$d \gamma=0.020 \mathrm{~mm}$} & $\mathrm{~m}=0.04$ & \multicolumn{3}{|c|}{$\mathrm{T}^{*}=700 \mathrm{~K}$} & & \\
\hline $\mathrm{T}, \mathrm{K}$ & $Q_{n} \mathrm{~J} /$ event & $\mathrm{X}$ & $\alpha_{\underline{X}}$ & $\mathrm{n}_{\mathrm{V}}^{\mathrm{T}} \mathrm{mm}^{-3}$ & $M_{X}$ & $\dot{P}_{X} \mathrm{~s}^{-1}$ & $R^{2}$ \\
\hline 663 & $2.14 \times 10^{-19}$ & $1.92 \times 10^{-2}$ & 1.00 & $3.07 \times 10^{2}$ & $2.33 \times 10^{-4}$ & 696.99 & 0.99 \\
\hline \multicolumn{8}{|c|}{$\mathrm{Fe}-12 \mathrm{wt} \% \mathrm{Cr}-9 \mathrm{wt} \% \mathrm{Ni}^{29}$} \\
\hline \multicolumn{2}{|c|}{$d \gamma=0.006 \mathrm{~mm}$} & $\mathrm{~m}=0.13$ & $\mathrm{~T}^{*}=270 \mathrm{~K}$ & $\mathrm{~T}=233$ & & & \\
\hline $\begin{array}{l}\text { Magnetic } \\
\text { Field, T }\end{array}$ & $Q_{n} \mathrm{~J} /$ event & $\mathrm{X}$ & $\alpha_{\underline{X}}$ & $\mathrm{n}_{\mathrm{v}}^{\mathrm{T}} \mathrm{mm}^{-3}$ & $M_{X}$ & $\dot{P}_{X} \mathrm{~s}^{-1}$ & $R^{2}$ \\
\hline 0 & $1.08 \times 10^{-19}$ & $8.97 \times 10^{-4}$ & 1.00 & $8.73 \times 10^{2}$ & $9.84 \times 10^{-6}$ & 0.026 & 0.97 \\
\hline 2 & $9.92 \times 10^{-20}$ & $3.50 \times 10^{-2}$ & 1.00 & $8.73 \times 10^{2}$ & $9.84 \times 10^{-6}$ & 0.59 & 0.97 \\
\hline 4 & $9.67 \times 10^{-20}$ & $9.58 \times 10^{-2}$ & 1.00 & $8.73 \times 10^{2}$ & $9.84 \times 10^{-6}$ & 1.64 & 0.98 \\
\hline 6 & $9.55 \times 10^{-20}$ & $2.20 \times 10^{-1}$ & 1.00 & $8.73 \times 10^{2}$ & $9.84 \times 10^{-6}$ & 3.52 & 0.99 \\
\hline 9 & $9.17 \times 10^{-20}$ & $2.5 \times 10^{-1}$ & 1.00 & $8.73 \times 10^{2}$ & $9.84 \times 10^{-6}$ & 63.04 & 0.99 \\
\hline
\end{tabular}




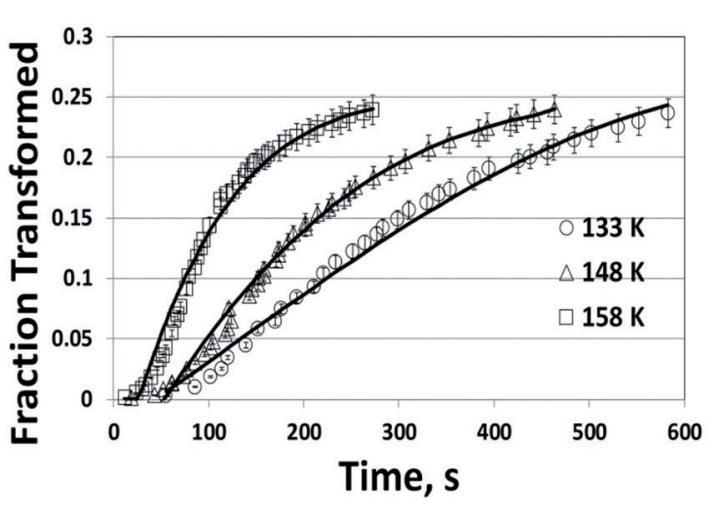

(a)

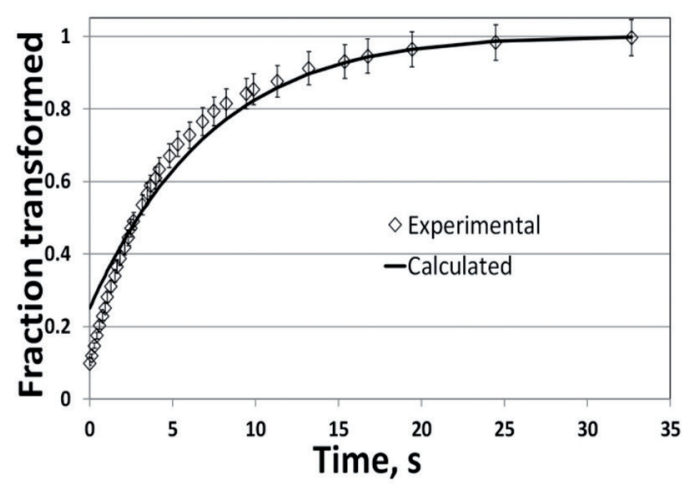

(c)

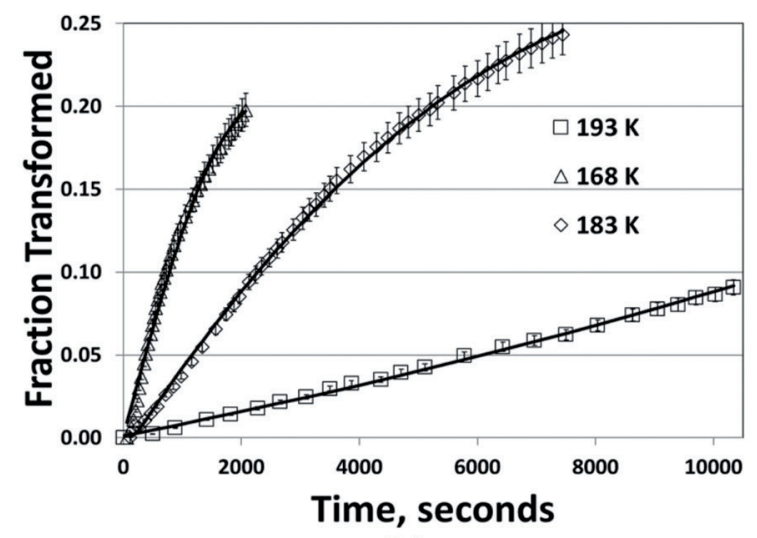

(b)

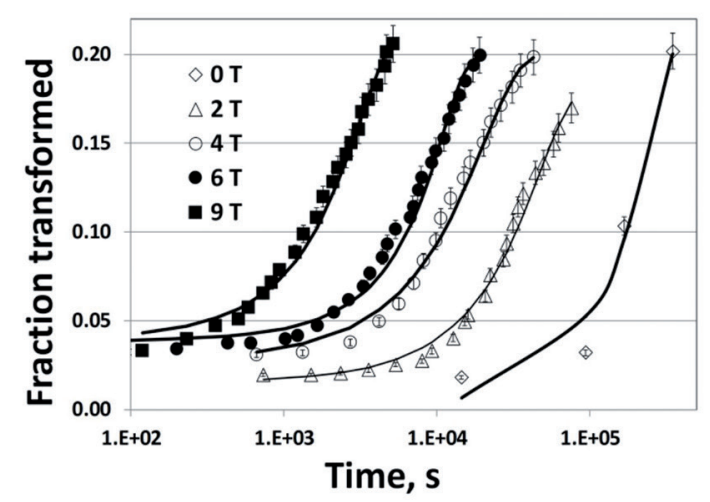

(d)

Figure 1: Time-dependent transformations (See Table 1)- (a-b) Isothermal martensite transformation curves of a Fe-Ni-Mn alloy ${ }^{19}$; (c) Fe-1.5wt $\%$ Mn-1.5wt $\%$-Si-0.3wt $\%$ Al- $0.2 w t \% \mathrm{C}^{27}$; (d)Fe- $12 \mathrm{wt} \% \mathrm{Cr}-9 \mathrm{wt} \% \mathrm{Ni}-4 \mathrm{wt} \% \mathrm{Mo}-2 \mathrm{wt} \% \mathrm{Cu}^{32}$.

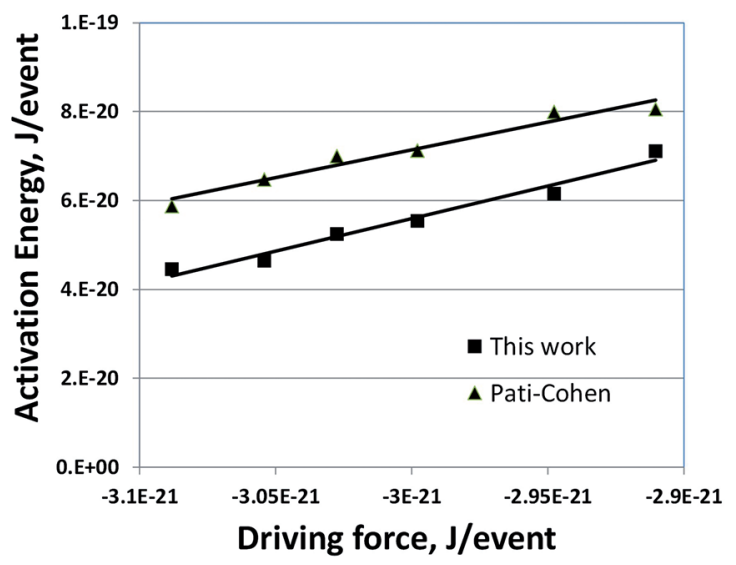

Figure 2: Activation energy of time-dependent martensitic transformation in $\mathrm{Fe}-24 \mathrm{wt} \% \mathrm{Ni}-3 \mathrm{wt} \% \mathrm{Mn}$ alloy as a function of the chemical driving force.

to the extended fraction transformed at $158 \mathrm{~K}$ and $148 \mathrm{~K}$ which are typical of the transformation in upper and lower temperature range. These linear graphs imply that $P_{X}$ is

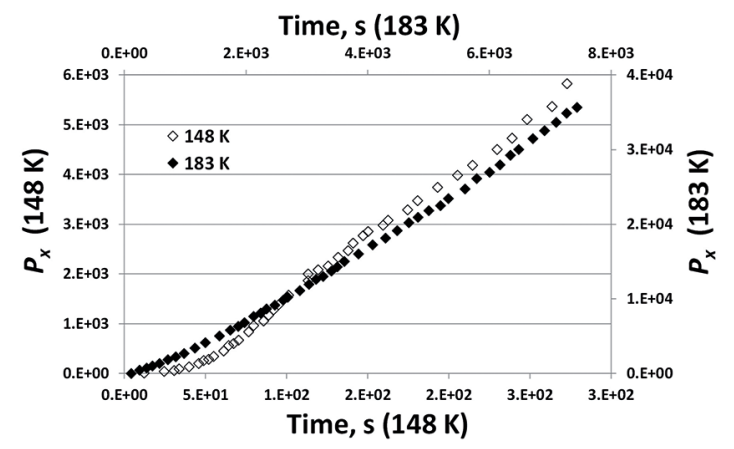

Figure 3: $\mathrm{Fe}-24 \mathrm{wt} \% \mathrm{Ni}-3 \mathrm{wt} \% \mathrm{Mn}$ transformation. Variation of the autocatalytic factor related to the martensite fraction transformed, $P_{X}$, with time at two temperatures for comparison.

also nearly invariant during the isothermal runs. However, $\dot{P}_{X}=d P_{X} / d t$ varies with the reaction temperature - see Table 1 .

Moreover, the convergence of the temperature-variations of $\dot{P}_{X}$ and initial rate of the martensite nucleation reported $i^{34}$ is remarkable, pointing to similarity in reaction path (nucleation mechanism) - see Figure 4. 


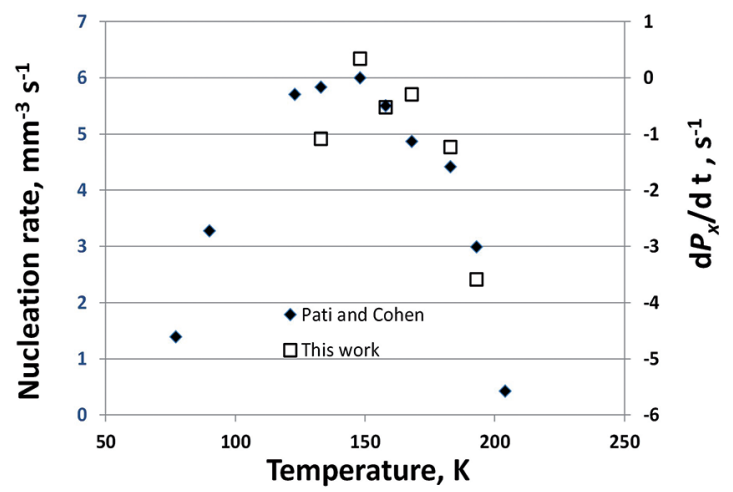

Figure 4: Comparison of temperature variation of the rate of autocatalytic transformation, $d P_{X} / d t$, with that of the initial rate of the isothermal martensite transformation in $\mathrm{Fe}-24 \mathrm{wt} \% \mathrm{Ni}-3 \mathrm{wt} \% \mathrm{Mn}^{34}$.

\subsection{Time-independent ("athermal") transformation}

The time-independent ("athermal") transformations curves in the datasets used in this section ${ }^{9,30,31}$ were properly fitted by using the JMAK relationship into Eq.(10). Most graphs exhibit fitting-correlations as high as 0.99 . Figure 5 shows the experimental data and corresponding fitted curves. The best-fittings of experimental data were obtained with values of $T^{*}$ just above the experimental $M_{S}$.

The values of $\bar{M}_{X}$ and $\alpha_{X}$ shown in Table 2 were obtained by fitting. Fitting $\alpha_{X}$ to linearize the dataset, permitted obtaining $\bar{M}_{X}$ by linear regression. The values of $\alpha_{X}$ approaching 2 strongly suggest that in these "athermal" transformations, self-accommodation (variant-selection) is important ${ }^{35-38}$.

Noteworthy, the graphs in Figure 6 show that $\mathrm{dP}_{X}{ }^{\prime}$ $\mathrm{dT}$ is nearly constant for a given steel composition. The martensite morphology is lath in the $\mathrm{Fe}-0.66 \mathrm{wt} \% \mathrm{C}$ and plate in the $\mathrm{Fe}-1.0 \mathrm{wt} \% \mathrm{C}$ steel. Constant $\mathrm{dP}_{X} / \mathrm{dT}$ reiterates that the autocatalytic process typified by $\alpha_{X} \rightarrow 2$ is essentially mechanical ${ }^{36}$.

Summing up, the utility of the proposed formalism was validated with independent databases. Moreover, the

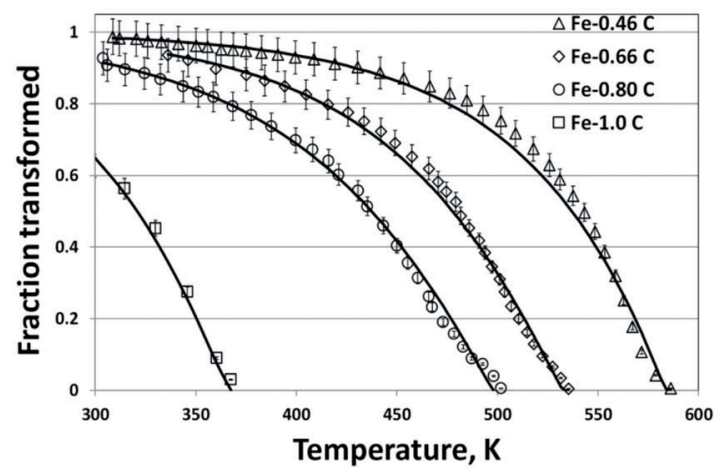

(a) analysis of the transformation curves in extended space correlates the mode of transformation, time-dependent ("isothermal") vs time-independent ("athermal") and the mechanism of autocatalysis qualified by the parameter $\alpha_{X}$. In the present context, autocatalysis is considered as a way for successful martensite nucleation events in the presence of entropic barriers.

\subsection{The autocatalytic path}

In this work we departed from the classical descriptions of the martensite transformation curves of previous works to consider the influence of entropic barriers in a phenomenological way. The referenced knowledge teaches that martensite's displacive aspect requires that correlated atoms simultaneously traverse the reaction path which imparts a probabilistic aspect to martensite nucleation because atomic mobility in the parent phase opposes to atomic correlation.

Assenting to that, it follows that martensite nucleation is more likely to occur at austenitic sites where atomic mobility is somehow limited. Hence, enhanced probability of nucleation events about previous formed martensite units should be expected, evidenced by the autocatalysis. In fact, Figure 4 shows that the rate of autocatalytic transformation and the rate of the initial isothermal transformation in $\mathrm{Fe}-$ $23 \mathrm{Ni}-4 \mathrm{Mn}$ converge, thence propagation at pre-existent sites or by autocatalysis stimulation are akin.

On the other hand, the values of $\alpha_{X}$ that characterize the "isothermal" $\left(\alpha_{X} \cong 1\right)$ and the "athermal" $\left(\alpha_{X}=2\right)$ transformation are remarkably different. Although $\alpha_{X}$ is a phenomenological parameter that sharp difference suggests different mechanisms of autocatalysis. To delve into this possibility, consider the transformation curves expressed as a function of the thermodynamic-kinetic advance given by the integration of Eq. 3

$$
\Xi=\frac{1}{\alpha_{X}-1} \ln \left(1+\frac{\left(\alpha_{X}-1\right)}{M_{X}} V_{V X}\right)
$$

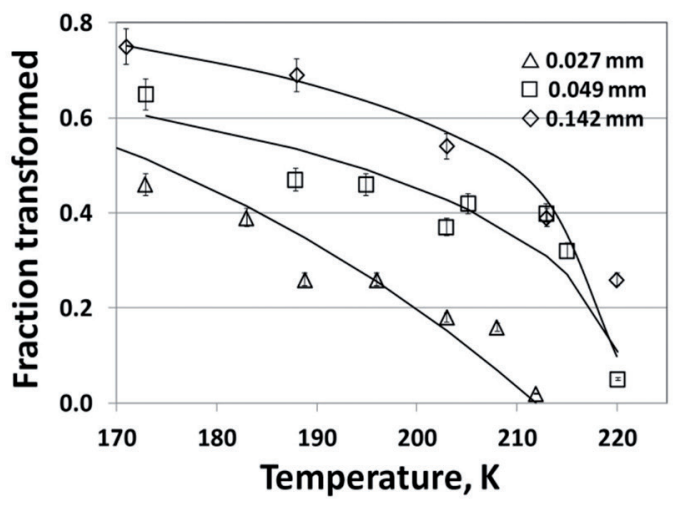

(b)

Figure 5: Time independent transformations (See Table 2.) - (a) Fe- $0.46 \mathrm{wt} \% \mathrm{C}$, Fe- $0.66 \mathrm{wt} \% \mathrm{C}$ steel, Fe- $0.80 \mathrm{wt} \% \mathrm{C}(0.130 \mathrm{~mm}$ grain intercept $)^{9,30}$; (b) Fe-31wt $\% \mathrm{Ni}-0.02 \mathrm{wt} \% \mathrm{C}(0.027-0.142 \mathrm{~mm} \text { grain intercept })^{31}$. 
Table 2: Time-independent transformations

\begin{tabular}{|c|c|c|c|c|c|c|}
\hline Ref. ${ }^{30}$ & $d \gamma, \mathrm{mm}$ & $T^{*}, \mathrm{~K}$ & $\alpha_{\mathrm{x}}$ & $\bar{M}_{X}$ & $-\mathrm{dP}_{\mathrm{X}} / d T, \mathrm{~K}^{-1}$ & $R^{2}$ \\
\hline $\mathrm{Fe}-1.0 \mathrm{wt} \% \mathrm{C}$ & $9.0 \times 10^{-2}$ & 368 & 2.20 & $4.65 \times 10^{-3}$ & 3.17 & 0.99 \\
\hline Ref. $^{9}$ & $d \gamma, \mathrm{mm}$ & $T^{*}, \mathrm{~K}$ & $\alpha_{\mathrm{x}}$ & $\bar{M}_{X}$ & $-\mathrm{dP}_{\mathrm{x}} / d T, \mathrm{~K}^{-1}$ & $R^{2}$ \\
\hline $\mathrm{Fe}-0.80 \mathrm{wt} \% \mathrm{C}$ & $1.3 \times 10^{-1}$ & 504 & 2.10 & $1.83 \times 10^{-2}$ & 0.70 & 0.99 \\
\hline Fe- $0.66 w t \% C$ & $1.3 \times 10^{-1}$ & 536 & 2.03 & $7.67 \times 10^{-3}$ & 1.80 & 0.99 \\
\hline $\mathrm{Fe}-0.46 \mathrm{wt} \% \mathrm{C}$ & $1.3 \times 10^{-1}$ & 587 & 1.96 & $3.88 \times 10^{-3}$ & 3.73 & 0.99 \\
\hline Ref. ${ }^{31}$ & $d \gamma, \mathrm{mm}$ & $T^{*}, \mathrm{~K}$ & $\alpha_{\mathrm{x}}$ & $\bar{M}_{X}$ & $-\mathrm{dP}_{\mathrm{x}} / d T, \mathrm{~K}^{-1}$ & $R^{2}$ \\
\hline $\mathrm{Fe}-31 w t \% \mathrm{Ni}-0.02 \mathrm{wt} \% \mathrm{C}$ & $14.2 \times 10^{-2}$ & 220 & 1.40 & $1.48 \times 10^{-1}$ & 0.15 & 0.89 \\
\hline $\mathrm{Fe}-31 \mathrm{wt} \% \mathrm{Ni}-0.02 \mathrm{wt} \% \mathrm{C}$ & $4.9 \times 10^{-2}$ & 221 & 1.5 & $7.93 \times 10^{-2}$ & 0.21 & 0.87 \\
\hline $\mathrm{Fe}-31 \mathrm{wt} \% \mathrm{Ni}-0.02 \mathrm{wt} \% \mathrm{C}$ & $2.7 \times 10^{-2}$ & 212 & 2.0 & $1.85 \times 10^{-3}$ & 9.87 & 0.92 \\
\hline
\end{tabular}

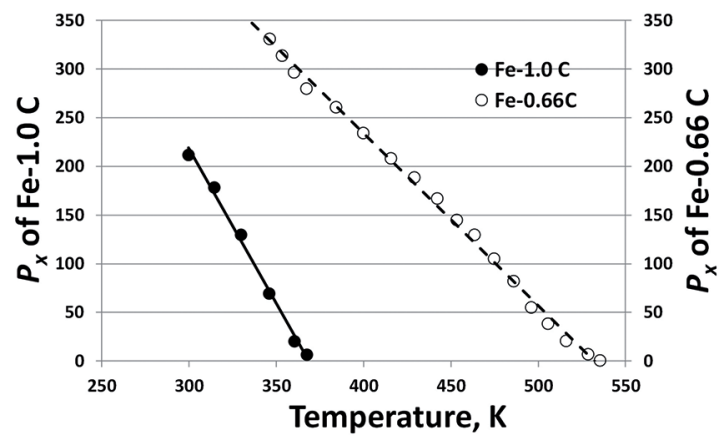

Figure 6: Temperature variation of the autocatalytic factor $P_{X}$.

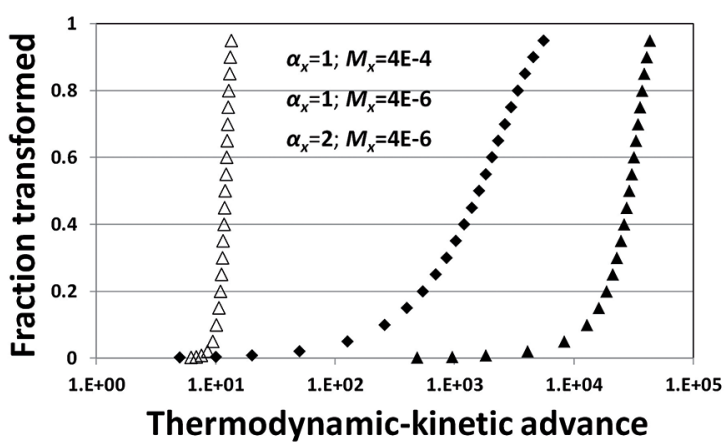

Figure 7: Martensite fraction transformed as a function of the thermodynamic-kinetic advance $\Xi$. Comparison of experimental (filled carats) and simulated results (triangles).

The reference chart in Figure 7, represented by filled carats, was generated with the parameters $\left(\alpha_{X} \cong 1, M_{X}=4.09 \times 10^{-4}\right.$ typical of the isothermal transformation in the Fe- $24 \mathrm{wt} \% \mathrm{Ni}$ $3 \mathrm{wt} \% \mathrm{Mn}$ alloy at $158 \mathrm{~K}$. The filled triangles simulate the isothermal transformation $\left(\alpha_{X} \cong 1\right)$ assuming a value of $M_{X}=4.09 \times 10^{-6}$ which means decreasing the probability of finding austenitic sites to initiate the transformation by two orders of magnitude. The open triangles simulate "athermal" transformation $\left(\alpha_{X}=2\right)$ in a material with $M_{X}=4 \times 10^{-6}$. It is worthy of emphasis that $M_{X}$ relates to the initial austenite. Observe that decreasing $M_{X}$ extended the initial ramp over larger values of $\Xi$, whereas setting $\alpha_{X}=2$ promoted a steeper ramp suggestive of burst-like transformations experimentally observed in some materials.

Here we propose that $a_{X}=2$ links to the formation of grouped units in auto-accommodated (shape-strain relaxing arrangements) ${ }^{36-40}$. This autocatalytic process may as well as relate to stress-assisted martensite nucleation in a plastic zone forming adjacent to a propagation event ${ }^{41}$. Comparing, $\alpha_{X} \approx$ 1 should reflect a less intense feedback from the relaxation of the transformation strains. We propose that $\alpha_{X} \approx 1$ stems from stress-accommodating micro-domains within the martensite unit ${ }^{14,39,42}$ as well as from slip during the motion of the martensite-austenite interface ${ }^{43-45}$.

Summing-up, we assert that the autocatalysis helps bypassing the entropic barriers. Autocatalysis stems from the relaxation of the transformation strains. Thus, isothermal martensite autocatalysis may be associated with strain relaxation by slip. Whereas athermal martensite autocatalysis can be attributed to strain relaxation by auto-accommodation. Thus, the "isothermal" and "athermal" autocatalysis are distinct merely by their modes of transformation strains relaxation which goes along with the early assertion by Entwisle and Feeney in ${ }^{44}$ that an "athermal martensite" autocatalytic burst is a fast "isothermal transformation".

\section{Summary and Conclusions}

The topics revisited during this analysis of martensite transformation curves in steels were consolidated into a formalism that balances the thermodynamic-kinetic aspects of the reaction with microstructural evolution of the martensite nucleation under the influence of entropic barriers.

The proposed formalism was validated with a database comprising steels of six distinct compositions. Despite the approximations lumped into the invoked JMAK relationship, fittings reaching 0.99 were generally observed. The approach to microstructure development in extended space underlies these prominent results. 
The analysis of the transformation curves supports the view that the autocatalytic path typical of martensite abbreviates the influence of entropic barriers.

The sharp difference between the values of the autocatalytic parameter $\alpha_{X}$ that characterizes the "isothermal" and the "athermal" martensitic transformation curves, reflects the difference of relaxation of transformation strains associated with autocatalysis in each case. Namely, relaxation by slip goes along with the isothermal mode of transformation, whereas auto-accommodation is typical of the "athermal" mode.

\section{Acknowledgements}

Thanks are due to Professor H. Goldenstein of University of São Paulo, for his assistance with the bibliography. P.R. Rios is grateful to Conselho Nacional de Desenvolvimento Científico e Tecnológico, CNPq, and to Fundação de Amparo à Pesquisa do Estado do Rio de Janeiro, FAPERJ, for financial support.

\section{References}

1. Harris WJ, Cohen M. Stabilization of the Austenite-Martensite Transformation. Transactions of the American Institute of Mining and Metallurgical Engineers. 1949;180:447-470.

2. Koistinen DP, Marburger RE. A general equation prescribing the extent of the austenite-martensite transformation in pure iron-carbon alloys and plain carbon steel. Acta Metallurgica. 1959;7(1):59-60.

3. Magee CL. The nucleation of martensite. In: Aaronson HI, ed. Phase transformations. Metals Park: ASM International; 1968. p. 115-156.

4. Borgenstam A, Hillert M, Ågren J. Critical temperature for growth of martensite. Acta Metallurgica et Materialia. 1995;43(3):945-954.

5. Borgenstam A, Hillert M. Activation energy for isothermal martensite in ferrous alloys. Acta Materialia. 1997;45(2):651662.

6. Yu HY. A new model for the volume fraction of martensitic transformations. Metallurgical and Materials Transactions A. 1997;28(12):2499-2506.

7. Borgenstam A, Hillert M. Nucleation of isothermal martensite. Acta Materialia. 2000;48(11)2777-2785.

8. Ghosh G, Olson GB. The kinetics of lath martensitic transformation. Journal de Physique IV: France. 2003;112:139-142.

9. Van Bohemen SMC, Sietsma J. Martensite formation in partially and fully austenitic plain carbon steels. Metallurgical and Materials Transactions A. 2009;40(5):1059-1068.

10. Lee SJ, Van Tyne CJ. A kinetics model for martensite transformation in plain carbon and low-alloyed steels. Metallurgical and Materials Transactions A. 2012;43(2):422-427.

11. Guimarães JRC, Rios PR. Modeling lath martensite transformation curve. Metallurgical and Materials Transactions A . 2013;44(1):24.
12. Huyan F, Hedström P, Borgenstam A. Modelling of the fraction of martensite in low-alloy steels. Materials Today: Proceedings. 2015;(Suppl. 3):S561-S564.

13. Kakeshita T, Kuroiwa K, Shimizu K, Ikeda T, Yamagishi A, Date M. A new model explainable for both the athermal and isothermal natures of martensitic transformations in Fe-Ni-Mn alloys. Materials Transactions, JIM. 1993;34(5):423-428.

14. Shankaraiah N, Murthy KPN, Lookman T, Shenov SR. Incubation times and entropy barriers in martensitic kinetics: Monte Carlo quench simulation of strain pseudospins. EPL (Europhysics Letters). 2010;92(3):36002.

15. Kastner O, Shneck RZ. On the entropic nucleation barrier in a martensitic transformation. Philosophical Magazine. 2015;95(12):1282-1308.

16. Shankaraiah N. Monte Carlo simulations of vector pseudospins for strains: Microstructures and martensitic conversion times. Journal of Alloys and Compounds. 2016;675:211-222.

17. Olson GB, Cohen M. A general mechanism of martensitic nucleation: Part I. General concepts and the FCC $\rightarrow \mathrm{HCP}$ transformation. Metallurgical Transactions A. 1976;7(12):18971923.

18. Raghavan V, Entwisle AR. Isothermal mechanism kinetics in iron alloys. In: The Physical Properties of Martensite and Bainite. Special Reports 93. London: Iron and Steel Institute; 1965; p. 29-37.

19. Pati SR, Cohen M. Kinetics of isothermal martensitic transformations in an iron-nickel-manganese alloy. Acta Metallurgica. 1971;19(12):1327-1332.

20. Avrami MJ. Kinetics of phase change. I general theory. The Journal of Chemical Physics. 1939;7(12):1103-1112.

21. Kolmogorov NA. The statistics of crystal growth in metals. Isvestiia Academii Nauk SSSR - Seriia Matematicheskaia. 1937;1:333-359.

22. Johnson WA, Mehl RF. Reaction kinetics in processes of nucleation and growth. Transactions AIME. 1939;135:416-441.

23. Rios PR, Villa E. Transformation kinetics for inhomogeneous nucleation. Acta Materialia. 2009;57(4):1199-1208.

24. Chiu SN, Stoyan D, Kendall WS, Mecke J. Stochastic Geometry and its Applications. $3^{\text {rd }}$ ed. Hoboken: John Willey \& Sons; 2013. 512 p.

25. Guimarães JRC, Rios PR. Initial nucleation kinetics of martensite transformation. Journal of Materials Science. 2008;43(15):52065210.

26. Cech RE, Turnbull D. Heterogeneous nucleation of the martensite transformation. Transactions AIME. 1956;206(2):124-132.

27. Kim D, Speer JG, De Cooman BC. Isothermal transformation of a CMnSi steel below the $\mathrm{M}_{\mathrm{S}}$ temperature. Metallurgical and Materials Transactions A. 2011;42(6):1575-1585.

28. Kim D, Lee SJ, De Cooman BC. Microstructure of low C steel isothermally transformed in the $\mathrm{M}_{\mathrm{S}}$ to $\mathrm{M}_{\mathrm{f}}$ temperature range. Metallurgical and Materials Transactions A. 2012;43(13):4967-4983.

29. San Martina D, van Dijk NH, Brück E, van der Zwaag S. The isothermal martensite formation in a maraging steel: A magnetic study. Materials Science and Engineering A. 2008;481-482:757761. 
30. Satyanarayan KR, Eliasz W, Miodownik AP. The effect of a magnetic field on the martensite transformation in steels. Acta Metallurgica. 1968;16(6):877-887.

31. Guimarães JRC, Gomes JC. Metallographic study of influence of austenite grain-size on martensite kinetics in Fe-31.9 Ni0.02C. Acta Metallurgica. 1978; 26(10):1591-1596.

32. San Martín D, Aarts KWP, Rivera-Díaz-del-Castillo PEJ, van Dijk NH, Brück E, van der Zwaag S. Isothermal martensitic transformation in a $12 \mathrm{Cr}-9 \mathrm{Ni}-4 \mathrm{Mo}-2 \mathrm{Cu}$ stainless steel in applied magnetic fields. Journal of Magnetism and Magnetic Materials. 2008;320(10):1722-1728.

33. Olson GB, Cohen M. Dislocation theory of martensitic transformation. In: Nabarro FRN, ed. Dislocations in Solids. Amsterdam: North-Holland; 1986. p. 295-407.

34. Pati SR, Cohen M. Nucleation of the isothermal martensitic transformation. Acta Metallurgica. 1969;17(3):189-199.

35. Zhang S, Morito S, Komizo Y. Variant selection of low carbon high alloy steel in an austenite grain during martensite transformation. ISIJ International. 2012;52(3):510-515.

36. Bokros JC, Parker ER. The mechanism of the martensite burst transformation in Fe-Ni single crystals. Acta Metallurgica. 1963;11(12):1291-1301.

37. Yeddu HK. Martensitic transformation in steels - a 3d phase field study. [Doctoral Thesis]. Stockholm: Royal Institute of Technology; 2012.
38. Heo TW, Chen LQ. Phase-field modeling of displacive phase transformations in elastically anisotropic and inhomogeneous polycrystals. Acta Materialia. 2014;76:68-81.

39. Loewy S, Rheingans B, Meka SR, Mittemeijer EJ. Unusual martensite-formation kinetics in steels: Observation of discontinuous transformation rates. Acta Materialia. 2014;64:93-99.

40. Loewy S, Rheingans B, Meka SR, Mittemeijer EJ. Modulated martensite formation behavior in Fe-Ni-based alloys; athermal and thermally activated mechanisms. Journal Materials Research. 2015;30(13):2101-2107.

41. Zhang W, Jin YM, Khachaturyan AG. Phase field microelasticity modeling of heterogeneous nucleation and growth in martensitic alloys. Acta Materialia. 2007;55(2):565-574.

42. Grujicic M, Olson GB, Owen WS. Mobility of martensitic interfaces. Metallurgical Transactions A. 1985;16(10):17131722.

43. Grujicic M, Olson GB. Dynamics of martensitic interfaces. Interface Science. 1998;6(1):155-164.

44. Entwisle AR, Feeney JA. The effect of austenitizing conditions on martensite transformation by bursts. In: Institute of Metals. The mechanism of phase transformation in crystalline solids. London: Institute of Metals; 1969. p. 156-161.

45. Mompiou F, Wu J, Zhang WZ. A preliminary in-situ TEM study of Martensite/Austenite Interface Migration in an Fe-20Ni5.4Mn alloy. Materials Today: Proceedings. 2015;2(Suppl. 3):S651-S654. 